\title{
Modelo de Interação entre Pares (MIP): viabilizando o ensino da Informática Educativa na Educação Infantil
}

\author{
David Machado ${ }^{1}$, Mariusa Warpechowski ${ }^{1}$, Douglas Vaz ${ }^{2}$ \\ ${ }^{1}$ Centro Universitário Cenecista de Osório (UNICNEC) - Osório - RS - Brasil \\ Curso de Licenciatura em Informática (UNICNEC) \\ ${ }^{2}$ Universidade LaSalle (UNILASALLE) - Canoas - RS - Brasil \\ Programa de Pós-graduação em Educação \\ david.machado.mvehotmail.com, mariusawlgmail.com, \\ douglasv.edulgmail.com
}

\begin{abstract}
Even with many benefits that the use of Educational Computing provides, there are still schools that lack of technological resources. This often makes it difficult or impossible to work with educational computing. In this way, this article proposes a model called the Model of Interaction between Peers (IMIP), which seeks to supply the demand of the number of students to few computers. The IMIP has applied in a Kindergarten Education class, of a public school of the North Coast of Rio Grande do Sul State, composed of 15 students. The results have showed that the methodology has been effective in the context where it was applied, since it was possible to use two personal computers for more than 15 students, so that they worked together and interacted in the construction of their knowledge.
\end{abstract}

Resumo. Mesmo com inúmeros benefícios que a utilização da Informática Educativa proporciona, ainda existem escolas que carecem de recursos tecnológicos. Isto, muitas vezes, dificulta ou inviabiliza o trabalho com a informática educativa. Desta maneira, este artigo propõe um método denominado de Modelo de Interação entre Pares (MIP), o qual busca suprir a demanda do número de alunos para poucos computadores. O MIP foi aplicado em uma turma de Educação Infantil, de uma escola pública do Litoral Norte do Rio Grande do Sul, constituída por 15 alunos. Os resultados mostraram que o método foi eficaz no contexto onde foi aplicada, pois foi possível utilizar dois computadores de uso pessoal para mais de 15 alunos, de modo que eles trabalhassem em conjunto e interagissem na construção do seu conhecimento.

\section{Introdução}

A informática na Educação Infantil é vista como um desafio ou muitas vezes como sinônimo de diversão ou brincadeira. Entretanto, por meio de uma abordagem educativa, a utilização da informática no contexto da Educação Infantil pode transformar a prática docente em algo mais dinâmico e aprazível, pois a tecnologia dá aos alunos a oportunidade de se expressar e dar asas à imaginação. A informática educativa pode ser entendida como uma modalidade em que o aluno se torna protagonista de sua 
aprendizagem, onde o computador é utilizado como um meio e não um fim (ROCHA, 2008).

Em virtude da era digital em que nos encontramos, faz-se necessário introduzir a informática desde cedo no ambiente educacional, uma vez que a inserção da informática nas primeiras idades pode ser vista como um fator de igualdade social (ROSA, 2010), pois permite que crianças mais desfavorecidas tenham acesso a tecnologia que em casa não possuem. A tecnologia, no que diz respeito aos recursos tecnológicos, ainda não faz parte da realidade de algumas escolas, e tampouco se faz presente nas práticas pedagógicas realizadas pelos professores. Tais evidências foram notadas na escola em que foi realizada a prática docente, pois se viu necessário introduzir a tecnologia no cotidiano dos alunos de uma turma de Educação Infantil.

Partindo do pressuposto salientado por Fino (2001), de que na falta ou escassez de recursos é viável utilizar os próprios alunos como recurso de instrução, pensou-se em "Como desenvolver um método que consiga empregar no mínimo dois computadores para todos os alunos". Portanto, foi elaborado o Modelo de Interação entre Pares (MIP), onde o aluno atua como recurso de instrução, compartilhando suas experiências com os colegas e ao mesmo tempo constrói seu conhecimento com base na interação entre pares (colegas).

O objetivo deste trabalho foi aplicar o MIP em uma turma de Educação Infantil para suprir a falta de recursos tecnológicos. Buscou-se trabalhar com atividades que envolvessem conceitos próximos às atividades que os alunos já haviam desempenhado ou que estavam sendo desenvolvidas. À vista disso, foram abordados alguns dos conceitos edição de texto e digitação, pois dessa maneira a criança se depara com as letras do teclado, e isso pode contribuir para o seu processo de alfabetização. Para isso foi utilizado o software Aperta Letra ${ }^{1}$.

O artigo está organizado da seguinte maneira, na seção 2 é abordada a informática educativa, na subseção 2.1 é apresentada a ferramenta de edição de texto utilizada, já na seção 3 é apresentado o Modelo de Interação entre Pares (MIP), a seção 4 descreve como o MIP foi aplicado, a seção 5 apresenta os resultados deste trabalho e na seção 6 são apresentadas as considerações finais.

\section{Informática Educativa}

Na visão de Valente (1993, p. 1) "para a implantação do computador na educação são necessários basicamente quatro ingredientes: o computador, o software educativo, o professor capacitado par usar o computador como meio educacional e o aluno".

Almeida (2000) diz que o computador é "[...] uma máquina que possibilita testar ideias ou hipóteses, que levam à criação de um mundo abstrato e simbólico, ao mesmo tempo em que permite introduzir diferentes formas de atuação e interação entre as pessoas". Contudo, Rocha (2008, p.2) ressalta que é necessário que a utilização do computador seja repensada, pois o computador acaba "[...] se transformando em um

\footnotetext{
${ }^{1} \mathrm{O}$ software Aperta Letra foi desenvolvido pela Apertaqual Educação que por sua vez, é uma empresa social criada para tornar as tecnologias acessíveis para Atores e Instituições Sociais. Mais informações em: http://apertaqual.org/.
} 
poderoso recurso de suporte à aprendizagem, com inúmeras possibilidades pedagógicas [...]" o que de certa forma, pressupõe em uma reformulação no currículo. Neste ponto de vista, o software educativo pode se tornar uma ferramenta relevante na Educação Infantil, pois o professor consegue desenvolver atividades que sejam atrativas e lúdicas, visto que esses fatores prendem a atenção dos pequenos.

Segundo Rocha (2008), numa perspectiva de Informática Educativa, o computador é utilizado como um meio e não um fim. Logo, a Informática Educativa permite o trabalho interdisciplinar às demais áreas do conhecimento. Isso vai de acordo com o que diz Guedes (2013, p. 410) ao dizer que "[...] o computador não serve apenas para realizar tarefas humanas, como somar, processar e ensinar, mas pressupõe o desenvolvimento das capacidades cognitivas e meta-cognitivas de cada indivíduo".

Embora intuitiva e divertida, a Informática Educativa é algo novo para os alunos de Educação Infantil, pois é uma modalidade onde são exigidas habilidades que muitas vezes não foram desenvolvidas antes. Sendo assim, é importante que sejam abordados conceitos que sirvam de base para que eles utilizem outros softwares educativos. Um exemplo disso seria introduzir alguns dos conceitos de edição de texto, pois o aluno deve dominar as habilidades que envolvam edição de texto e digitação para que possa dominar outras ferramentas, uma vez que a digitação pode estimular a alfabetização desses alunos, bem como o desenvolvimento de habilidades motoras, assim como afirma Pellegrini:

"[...] na execução da habilidade motora de clicar ou digitar, a criança deve apresentar o controle das partes do corpo que estão em movimento para a execução da tarefa e os fatores deste equilíbrio motor e da coordenação, em conjunto com a força produzida e a agilidade, velocidade e energia, que são considerados determinantes do desempenho motor da criança." (PELLEGRINI apud ARAGÃO, 2010, p. 7).

O software educativo é um elemento importante no contexto da Educação Infantil, pois dá a oportunidade ao aluno de aprender "brincando", de modo que ele construa seu próprio conhecimento sem ser punido pelos seus erros (Rosa, 2010). A autora ainda afirma que:

“[...] os recursos multissensoriais disponíveis nos softwares educativos podem contribuir grandemente para o desenvolvimento de habilidades como a percepção visual, o raciocínio lógico e a criatividade importante para o desenvolvimento cognitivo e para a construção de conhecimentos primordiais para séries posteriores [...]”. (Rosa, 2010, p.3).

\subsection{O software Aperta Letra}

O Aperta Letra trata-se de um software de edição de texto para crianças utilizarem com autonomia todos os recursos que envolvam formatação de texto e outras funções como recortar, copiar, colar, desfazer, salvar e imprimir. O Aperta Letra possui uma interface lúdica e interativa, que pode ser conferida na Figura 1. 


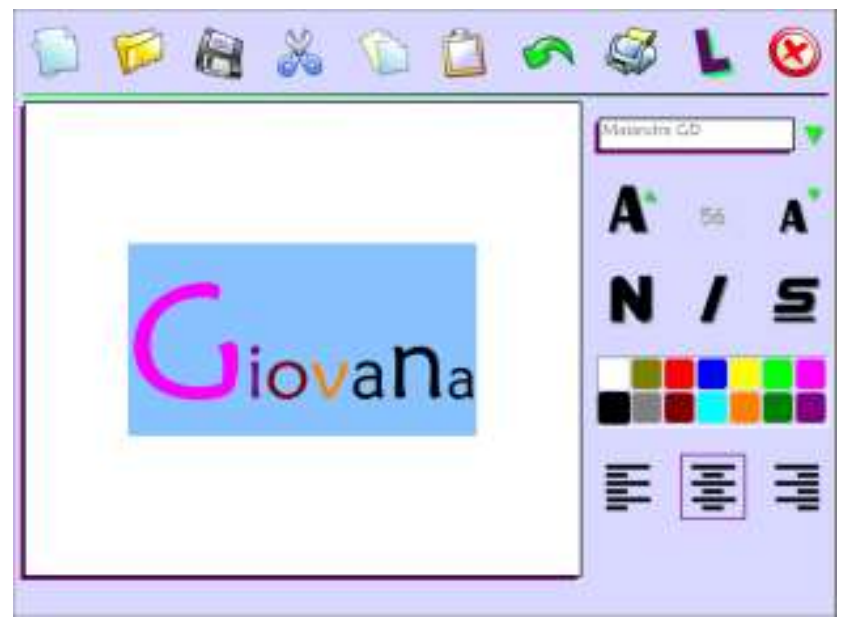

Figura 1. Interface do software Aperta Letra

O software Aperta Letra em relação aos demais softwares editores de texto, possui uma interface lúdica. De acordo com Dallabona e Mendes "[...] as atividades lúdicas, os jogos, permitem liberdade de ação, pulsão interior, naturalidade e, consequentemente, prazer que raramente são encontrados em outras atividades escolares" (2004, p. 10). Em virtude disso, o software Aperta Letra foi escolhido pelo fato de que por meio dele é possível trabalhar com os conceitos de edição de texto de forma divertida. É importante trabalhar com estes conceitos desde cedo, pois o aluno pode estar familiarizado com estes conceitos quando for utilizá-los no decorrer da sua trajetória escolar ou acadêmica.

\section{Modelo de Interação entre Pares (MIP)}

$\mathrm{Na}$ falta ou escassez de recursos tecnológicos, se torna necessária a elaboração de métodos diversificados. Tais métodos, na perspectiva de Fino (2001), podem utilizar os próprios estudantes como recursos de instrução, através dos quais se "ensinam" uns aos outros. Sendo assim, foi feita uma análise do contexto educacional dos alunos, e pensada numa maneira com a qual fosse possível utilizar eles próprios como recursos, de modo que fossem utilizados poucos computadores para todos os alunos. Assim definiu-se o Modelo de Interação entre Pares (MIP).

O MIP trata-se de um método, de caráter aplicável, que foi idealizado com o intuito de viabilizar a introdução da informática educativa em cenários que carecem de recursos tecnológicos, ao mesmo tempo em que procura propiciar momentos de interação entre pares de alunos, no que tange aos conteúdos que estão sendo abordados. Para a aplicação do método são necessários de no mínimo 2 computadores, que podem ser tanto do tipo Notebook quanto do tipo Desktop. A Figura 2 mostra o funcionamento do MIP, onde a letra "P" representa o professor que irá articular a prática e as letras de "A" a "F" simbolizam cada aluno envolvido. 


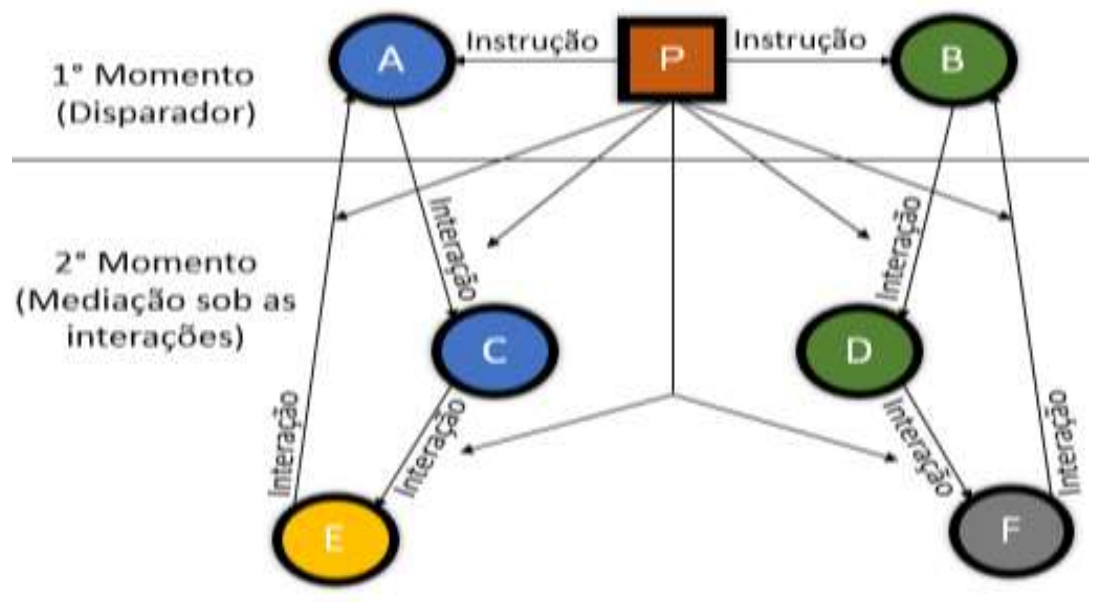

Figura 2. Funcionamento do MIP

O primeiro momento do MIP é caracterizado pela instrução, por parte do professor "P", aos alunos "A" e "B" sobre o funcionamento das atividades que serão realizadas no computador. Após os alunos finalizarem as atividades, inicia-se o segundo momento, onde um aluno "C" e um aluno "D" são convidados para participar das atividades. O aluno " $\mathrm{C}$ " senta ao lado do aluno "A" e o aluno "D" senta ao lado do aluno "B". Neste momento, as instruções são dadas pelos alunos "A" e "B", onde o aluno "A" instrui o aluno " $C$ " e o aluno " $B$ " instrui o " $D$ ". Um novo ciclo se inicia ao chegar mais pares de alunos, um aluno "E" e um aluno "F", que por sua vez, são instruídos pelos alunos " $C$ " e " $D$ ". A instrução de um aluno ao outro resulta num processo de interação, que deve ser mediado constantemente pelo professor "P".

O professor, representado por "P", como mostra a figura 2, tem um papel fundamental no decorrer da aplicação do Modelo, visto que é ele quem vai auxiliar os alunos nas possíveis dúvidas que podem surgir, bem como, nos processos de interação entre os pares de alunos. Estas constatações vão ao encontro do que diz Pimentel (2011, p. 4), pois de acordo com o autor é papel do professor organizar "[...] os momentos e conceitos, ajudando os alunos a perceberem a complementaridade de seus saberes, como também a necessidade de aprofundar alguns conceitos absorvidos [...]”. Então, é imprescindível que o professor assuma uma postura de mediador, de modo que fique presente durante todo o processo de interação entre os pares.

King (1997) ressalta que “[...] a aprendizagem de conhecimentos e de habilidades ocorre num contexto social no interior do qual um adulto ou uma criança, mais aptos, guiam a actividade de um indivíduo menos apto". Nesse caso, o MIP propõe um maior envolvimento entre os alunos, onde eles obtêm experiência na interação com a ferramenta, ou com o conteúdo com o qual está envolvido, para que posteriormente auxilie o colega ao lado, sanando as dúvidas ou até mesmo criando novos conhecimentos, de forma colaborativa.

O MIP oferece a possibilidade de o aluno instruir a atividade do colega ao lado. Neste contexto, Colaço enfatiza que, no momento em que os alunos "[...] orientam, apoiam, dão respostas e inclusive avaliam e corrigem a atividade do colega, com o qual dividem a parceria do trabalho, assumem posturas e gêneros discursivos semelhantes aos do professor" (2004, p. 339). Portanto, promover o lado instrutivo dos alunos 
VI Congresso Brasileiro de Informática na Educação (CBIE 2017)

Anais do XXIII Workshop de Informática na Escola (WIE 2017)

pressupõe o desenvolvimento da capacidade comunicativa, pois de acordo com Gonçalves (2007, p. 4), "Quanto mais a criança puder falar em diferentes situações como contar história, explicar uma brincadeira, solicitar ajuda, contar o que fez em casa mais ela ampliará sua capacidade comunicativa”.

\section{Metodologia}

A prática docente ocorreu em um encontro de quatro horas, em uma turma de Educação Infantil de uma escola pública do Litoral Norte do Rio Grande do Sul. A turma era composta de 15 alunos com idades entre 4 e 5 anos e para a aplicação do método foram utilizados dois computadores.

No primeiro momento do MIP, os alunos " $\mathrm{A}$ " $\mathrm{e}$ " $\mathrm{B}$ " foram instruídos pelo professor "P" sobre o funcionamento do software Aperta Letra. Para os demais alunos, foram distribuídos jogos pedagógicos (jogos de memória quebra cabeças, blocos lógicos, etc.). O objetivo da atividade foi apresentar a interface do software e fazer com que os alunos digitassem o próprio nome, com o auxílio de um papel cartolina que continha seu nome, ou outros nomes próprios, utilizando as funções de edição de texto: selecionar, recortar, colar, alterar cor, tamanho e tipo de fonte do texto. Esperou-se que ao realizar a atividade fossem capazes de:

I) reconhecer, identificar e manusear corretamente algumas funções do teclado: teclas alfabéticas, teclas numéricas, espaço, Enter e Backspace;

II) digitar nomes próprios;

II) formatar os nomes digitados; e

IV) dominar as funções recortar, copiar e colar.

A Figura 3 mostra o momento inicial da instrução do professor "P" aos alunos "A" e "B".

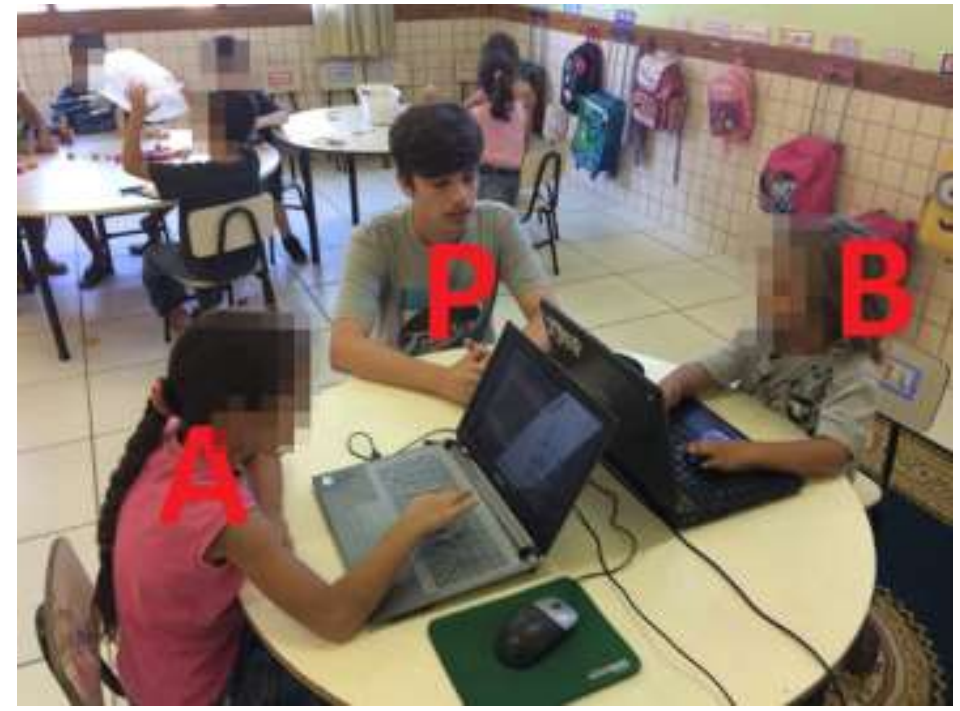

Figura 3. Primeiro momento do MIP

Em seguida, como mostra a Figura 4, foram convidados um aluno "C" e "D" para realizar a atividade. Neste momento, os alunos " $A$ " $\mathrm{e}$ " $\mathrm{B}$ " foram os encarregados de 
instruir os alunos "C" e "D", sobre como usar o editor de texto. Então, a função destes alunos foi a de instruir e auxiliar o colega ao lado. Este processo de interação entre os pares foi mediado pelo professor, pois na medida que surgiam dúvidas o professor intervinha, auxiliando os alunos.

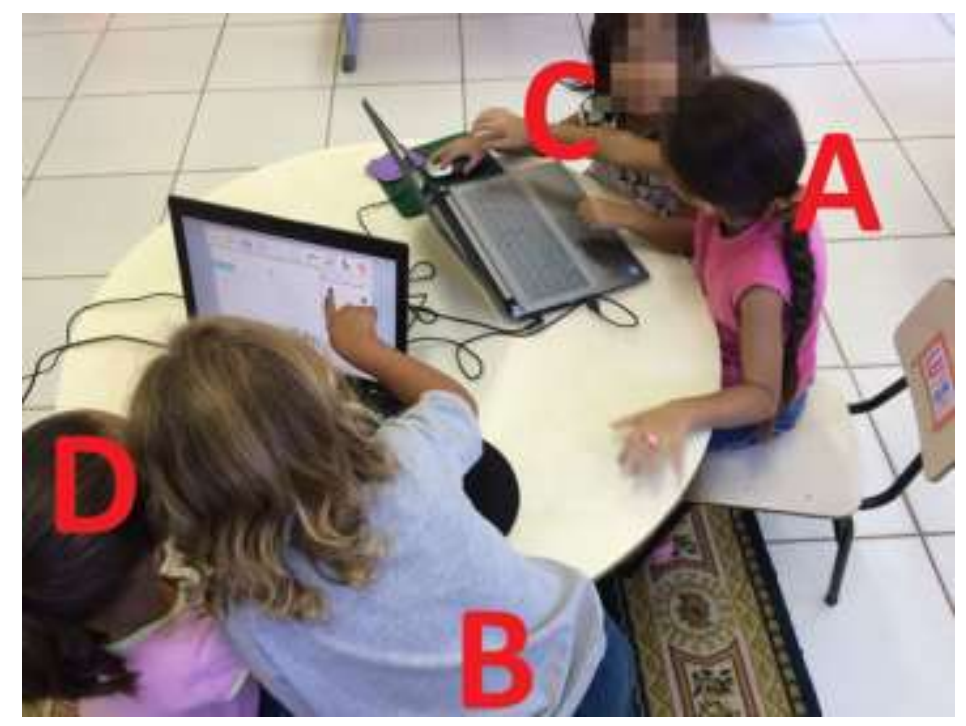

Figura 4. Segundo momento do MIP

E assim, sucessivamente, todos os 15 alunos participaram das interações que envolveram mediações do professor, quando necessário.

\section{Resultados}

Durante a aplicação do MIP, todos os alunos conseguiram usufruir ao máximo a utilização do software, explorando todas as funcionalidades apresentadas pelo professor. Os alunos compreenderam o processo e conseguiram realizar as atividades bem como, atuaram de maneira esperada nas interações.

As interações impactaram na aprendizagem dos alunos, pois possibilitaram com que eles mesmos fossem utilizados como recursos com o objetivo de guiar os colegas na realização das atividades. Esta constatação vai de acordo com o que diz King (1997), ao mencionar o fato de que a aprendizagem ocorre em ambiente social, onde um aluno mais apto guia um aluno menos apto.

No geral, as interações ocorreram de forma tranquila, no entanto, durante a troca dos pares, alguns alunos resistiram em ceder o lugar para o próximo colega ser o instrutor. Isso mostra que o aluno não apenas teve interesse em utilizar o software, mas também em acompanhar e auxiliar o colega. Importante mencionar um trecho dito por um dos alunos no momento de interação entre os pares: "Esse botãozinho serve para aumentar as letras, aí você pode selecionar só a primeira letra para deixar ela grande, igual no papelzinho". Notou-se, então, que houve um certo compartilhamento de estratégias entre os alunos, as quais foram obtidas por meio da interação com a ferramenta.

No decorrer do processo de interação, notou-se que os alunos elaboravam e compartilhavam estratégias, as quais não foram apresentadas pelo professor, um exemplo disso, foi a do trecho mencionado anteriormente, onde um dos alunos percebe 
que pode aumentar o tamanho de apenas uma letra e compartilha esse conhecimento com os outros colegas. Isso vai de encontro com o que diz Almeida (2000), pois o MIP possibilitou com que os alunos formulassem hipóteses, testassem essas hipóteses e ainda, compartilhassem seus conhecimentos obtidos durante a realização das atividades, de forma interativa. Portanto, é evidente que o MIP proporcionou uma construção colaborativa de conhecimentos.

Notou-se, também, que as instruções que eram dadas pelos alunos, em comparação às instruções dadas pelo professor no primeiro momento do modelo, não geravam tantas dúvidas, pois os alunos experimentavam as funções da ferramenta na medida em que os alunos instruíam. Diferente de quando o professor instruía, pois os alunos ficavam atentos ouvindo as instruções e só depois colocam em prática.

Houve momentos em que foi necessário que o professor mediasse a interação dos alunos, pois ocorreu de alguns alunos que estavam instruindo em vez de instruir, tentavam realizar a atividade para o colega.

No grupo que estava trabalhando com jogos pedagógicos, havia diálogos entre os alunos, onde já haviam passado pelas atividades e aqueles que não tinham tido a experiência. Este momento foi significativo, pois deixou os alunos mais curiosos e ansiosos em realizar as atividades.

\section{Considerações Finais}

O objetivo deste trabalho foi atingido, pois foi possível trabalhar com conceitos de edição de texto de forma dinâmica e interativa, utilizando os próprios alunos como recurso de instrução.

De um modo geral, o MIP viabilizou o ensino através da informática, pois num contexto onde não existia número suficiente de computadores, ele se mostrou eficaz em atender a demanda do número de alunos, visto que eles mesmos foram utilizados como recurso. Por ter se mostrado eficiente no contexto onde foi aplicado, o MIP também pode ser utilizado de forma interdisciplinar, pois da mesma maneira com que foram trabalhados conceitos de edição de texto, o professor pode trabalhar outros conceitos relacionados a outras disciplinas.

O MIP pode ser uma alternativa para aquelas escolas que carecem de recursos tecnológicos e que queiram utilizar a tecnologia como apoio às atividades realizadas pelos alunos, visto que necessita de no mínimo dois computadores.

Pode-se perceber que o MIP proporcionou aos alunos situações onde eles observavam a prática do colega ao lado e criavam estratégias que eram compartilhadas entre eles. Esse compartilhamento de experiências pode ser muito importante, em razão de que ele, ao observar a prática do colega, pode aperfeiçoar sua estratégia e refazê-la em outro momento.

Além da capacitação em utilizar o computador como meio educacional, que é um dos quatro ingredientes mencionados por Valente, o professor deve criar métodos que viabilizem a introdução da Informática Educativa, não se prendendo à falta de recursos. Métodos que por sua vez, assim como o MIP, utilizam os próprios alunos como recurso e propõem uma maior interação entre eles. Isso vai de acordo ao que diz King quando salienta que a aprendizagem acontece num meio social. 
VI Congresso Brasileiro de Informática na Educação (CBIE 2017)

Anais do XXIII Workshop de Informática na Escola (WIE 2017)

\section{Referências}

ALMEIDA, M E de. (2000). Informática e formação de professores. Brasília: Ministério da Educação.

ARAGÃO, Deise da Silva; NEZ, Egeslaine de. (2010). Jogos Educativos com o uso do computador na Educação Infantil. In: II Simpósio Nacional de Educação.

DALLABONA, S. R.; MENDES, S. M. S. (2004). O lúdico na Educação Infantil: jogar, brincar, uma forma de educar. Revista de divulgação técnico-científica do ICPG, V.1, N.4 P. 107-112.

COLAÇO, V. de F. R. (2004). Processos interacionais e a construção de conhecimento e subjetividade de crianças. Psicologia: Reflexão e Crítica, Porto Alegre, v. 17, n. 3, p. 333-340.

FINO, C. N. (2001). Vygotsky e a zona de desenvolvimento proximal (ZPD): três implicações pedagógicas. Revista Portuguesa de Educação, Vol 14 (2), 273-291.

GONÇALVES, Cristiane Januário; ANTONIO, Débora Andrade. (2008). As Múltiplas Linguagens no Cotidiano das Crianças. Periódicos UFSC. Florianópolis.

GUEDES, Anibal Lopes et al. (2013). Perspectivas do uso da Robótica Educativa na Educação Infantil e no Ensino Fundamental. In: Anais do XIX Workshop de Informática na Escola. p. 410.

KING, A. (1997). “Ask to THINK-TEL WHY: A Model of Transactive Peer Tutoring for Scaffolding Higher Level Complex Learning". Educational Psychologist, 32,4, pp. 221-235.

PIMENTEL, F.S.C. (2011). O papel da interação entre pares simétricos na construção de mapas conceituais. In $17^{\circ}$ Congresso Internacional de Educação a Distância.

ROCHA, S. (2008). "O Uso do Computador na Educação: a Informática Educativa". Revista Espaço Acadêmico, n. 85.

ROSA, C. P. (2010). O computador como ferramenta pedagógica na Educação Infantil. IF-AM.

VALENTE, J. A. (1993). Computadores e conhecimento: repensando a educação. Campinas: UNICAMP. 